\title{
DFT Study of the Electronic Structure of Cubic-SiC Nanopores with a C-Terminated Surface
}

\author{
M. Calvino, ${ }^{1}$ A. Trejo, ${ }^{1}$ M. I. Iturrios, ${ }^{2}$ M. C. Crisóstomo, ${ }^{2}$ \\ Eliel Carvajal, ${ }^{1}$ and M. Cruz-Irisson ${ }^{1}$ \\ ${ }^{1}$ Instituto Politécnico Nacional, ESIME Culhuacan, Avenida Santa Ana 1000, 04430 Distrito Federal, Mexico \\ ${ }^{2}$ Instituto Politécnico Nacional, CECyT, No. 8 Narciso Bassols, Avenida de las Granjas 618, 02530 Distrito Federal, Mexico \\ Correspondence should be addressed to M. Cruz-Irisson; irisson@ipn.mx
}

Received 25 November 2013; Revised 31 January 2014; Accepted 7 February 2014; Published 1 June 2014

Academic Editor: Sun-Hwa Yeon

Copyright (C) 2014 M. Calvino et al. This is an open access article distributed under the Creative Commons Attribution License, which permits unrestricted use, distribution, and reproduction in any medium, provided the original work is properly cited.

\begin{abstract}
A study of the dependence of the electronic structure and energetic stability on the chemical surface passivation of cubic porous silicon carbide ( $\mathrm{pSiC}$ ) was performed using density functional theory (DFT) and the supercell technique. The pores were modeled by removing atoms in the [001] direction to produce a surface chemistry composed of only carbon atoms (C-phase). Changes in the electronic states of the porous structures were studied by using different passivation schemes: one with hydrogen $(\mathrm{H})$ atoms and the others gradually replacing pairs of $\mathrm{H}$ atoms with oxygen $(\mathrm{O})$ atoms, fluorine $(\mathrm{F})$ atoms, and hydroxide $(\mathrm{OH})$ radicals. The results indicate that the band gap behavior of the $\mathrm{C}$-phase $\mathrm{pSiC}$ depends on the number of passivation agents (other than $\mathrm{H}$ ) per supercell. The band gap decreased with an increasing number of $\mathrm{F}, \mathrm{O}$, or $\mathrm{OH}$ radical groups. Furthermore, the influence of the passivation of the $\mathrm{pSiC}$ on its surface relaxation and the differences in such parameters as bond lengths, bond angles, and cell volume are compared between all surfaces. The results indicate the possibility of nanostructure band gap engineering based on $\mathrm{SiC}$ via surface passivation agents.
\end{abstract}

\section{Introduction}

Silicon carbide $(\mathrm{SiC})$ has been identified as an alternative power semiconductor material because of its chemical inertness, high thermal conductivity and stability, low thermal expansion coefficient, and wide band gap [1,2]. In particular, the $\beta$-SiC polytype is suitable for high-frequency power devices due to its high electron mobility and high electron saturation velocity, which make it a leading alternative to $\mathrm{Si}$ for applications in harsh environments [3, 4].

Cubic $\mathrm{SiC}$ can be synthesized in a variety of nanostructures, such as pores or nanowires. In particular, porous $\beta$ $\mathrm{SiC}(\mathrm{pSiC})$ has attracted considerable attention because this type of nanostructure provides a large highly reactive internal surface area, leading to its potential application as a sensing material [5]. pSiC can be used as an ideal solid-state gassensing material under harsh conditions due to its chemical stability at corrosive temperatures [5]. Furthermore, $\mathrm{pSiC}$ has been experimentally shown to display photoluminescence $(\mathrm{PL})$, the intensity and stability of which are dependent on its surface composition, which may extend its application to optoelectronics, communications, sensing applications, ultraviolet detection, and luminescent probes for medical imaging [6-8], specially hydroxide groups on the pore surface which have been shown to reduce the energy band gap thus decreasing the intensity of the lower energy PL peaks in comparison with the $\mathrm{H}$ case [9]. Furthermore it has been observed in porous $\mathrm{Si}$ that $\mathrm{Si}-\mathrm{O}-\mathrm{Si}$ or $\mathrm{Si}=\mathrm{O}$ bonds can produce trap states in the band gap generating PL pinning and enhancing $[10,11]$. These effects are produced by electrons from the conduction band minimum retained by the trap states in gap, and thus the population inversion between the top of the valence band and the trap states is possible due to the longer lifetime of the trapped electrons [11].

For such applications, it is critical to understand the effects of surface modifications on the electronic band structure of $\mathrm{pSiC}$; however the theoretical characterization of the effects of chemical agents on the electronic structure of Cterminated $\mathrm{SiC}$ is nonexistent (to the best of our knowledge); 


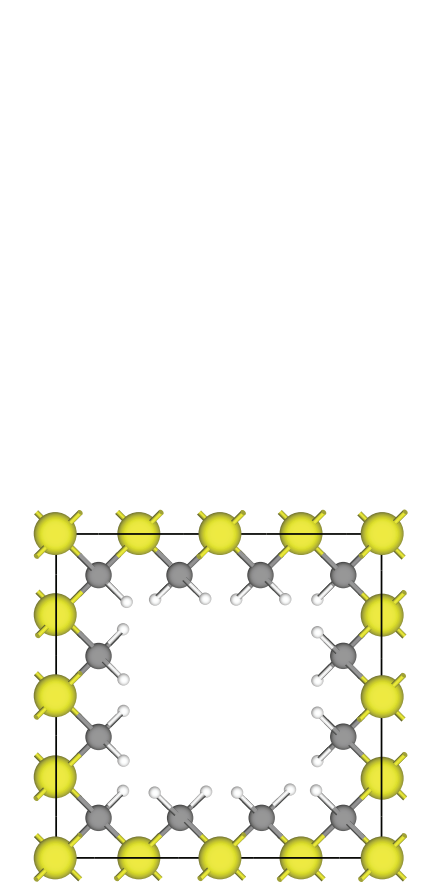

(a) Full $\mathrm{H}$

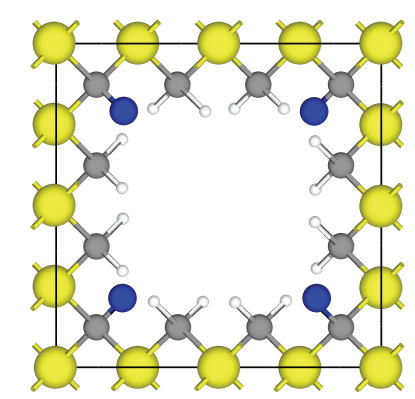

(b) $\mathrm{H}+\mathrm{F}$

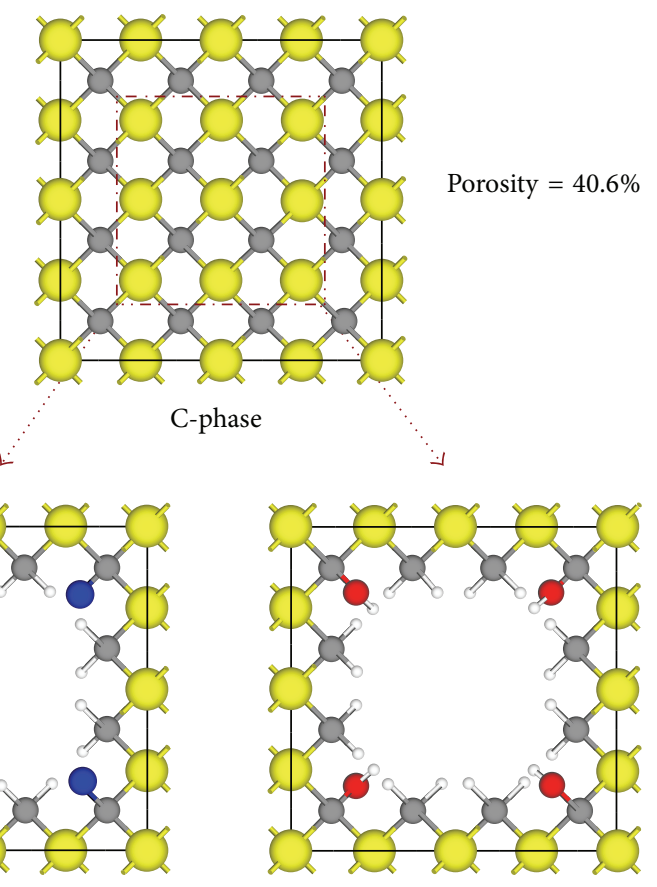

(c) $\mathrm{H}+\mathrm{OH}$

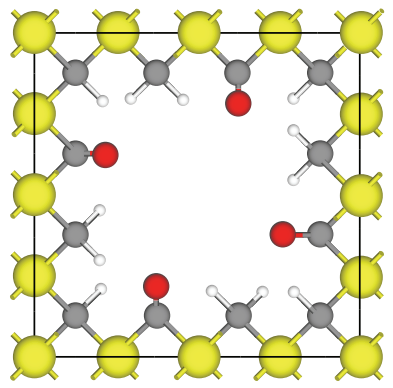

(d) $\mathrm{H}+\mathrm{O}$

Figure 1: Top view of $\mathrm{pSiC}$ with (a) full $\mathrm{H}$, (b) $\mathrm{H}+\mathrm{F}$, (c) $\mathrm{H}+\mathrm{OH}$, and (d) $\mathrm{H}+\mathrm{O}$ surface passivation. The dotted line represents the atoms removed from the 32-atom $\mathrm{SiC}$ supercell.

hence, this work discusses the effects of different surface passivation species on the structure and electronic properties of $\mathrm{pSiC}$. We performed a study of porous structures that exhibit a surface exclusively composed of $\mathrm{C}$ atoms and analyzed the changes in its electronic states using different passivation agents, including hydrogen $(\mathrm{H})$, fluoride $(\mathrm{F})$, oxygen $(\mathrm{O})$, and hydroxide $(\mathrm{OH})$.

\section{Methods}

The nanopores were modeled with the supercell technique $[12,13]$ by removing columns of atoms in the [001] direction of an otherwise perfect $\mathrm{SiC}$ crystal; this direction was chosen due to the experimental evidence of porous semiconductors such as silicon and germanium being synthetized in this particular direction and some works with $\mathrm{pSiC}$ grown on (001) $\mathrm{Si}$ substrates [14, 15]; furthermore, in the [001] direction, the $3 \mathrm{C}-\mathrm{SiC}$ can be viewed as being built up from successive $\mathrm{Si}$ and $\mathrm{C}$ layers. The (001) surface can be different stoichiometries, depending on whether the last plane is $\mathrm{Si}$ - or C-terminated [16]. To this end, a supercell of 32 atoms was created by attaching four eight-atom unit cells of $\mathrm{SiC}$, each with a lattice parameter of $a=4.3596 \AA$. Due to the binary nature of SiC, it is possible to obtain various surface configurations in the porous structures. In particular, the pores to be analyzed in this paper have a morphology that allows for a surface that is composed only of carbon atoms (C-phase). The selected porosity (ratio between the atoms removed and total atoms in the supercell) was $p=40.6 \%$, corresponding to 13 removed atoms (9 $\mathrm{Si}$ and $4 \mathrm{C}$ atoms) from a 32 -atom supercell, thus achieving the C-phased surface. This configuration was chosen based on the experimental evidence that the surface of pSiC is mainly composed of a C-rich phase [7, 17]. All surfacedangling bonds were initially saturated with $\mathrm{H}$ atoms. To study the effects of different chemical passivation agents on the electronic and structural properties of $\mathrm{pSiC}$, the hydrogen atoms of the surface were gradually replaced with $\mathrm{F}(\mathrm{H}+\mathrm{F})$, $\mathrm{OH}$ radicals $(\mathrm{H}+\mathrm{OH})$, and $\mathrm{O}(\mathrm{H}+\mathrm{O})$ atoms. The investigated limit cases were the replacement of four $\mathrm{H}$ atoms in the $\mathrm{H}+\mathrm{F}$ and $\mathrm{H}+\mathrm{OH}$ passivations at the pore corners as shown in Figures $1(\mathrm{~b})$ and $1(\mathrm{c})$, whereas eight $\mathrm{H}$ atoms were replaced for the $\mathrm{H}+\mathrm{O}$ case, as shown in Figure $1(\mathrm{~d})$.

The electronic properties of the $\mathrm{pSiC}$ were calculated using the first-principles density functional theory scheme through the CASTEP code [18] based on a generalized gradient approximation with a revised version of the PerdewBurke-Ernzerhof (RPBE) exchange-correlation functional [19] and norm-conserving pseudopotentials [20]. The cutoff energy used was $850 \mathrm{eV}$ with the Monkhorst-Pack [21] grids up to $3 \times 3 \times 6$. All structures were relaxed using the BFGS scheme [22] to obtain their minimum energy configuration, thus resulting in structural changes in the surface of the nanopores, where the maximum internal forces in the structures were $0.02 \mathrm{eV} / \AA$.

\section{Results and Discussion}

Figure 2 presents the electronic band structures of $\mathrm{pSiC}$ with different chemical passivation schemes alongside the bulk crystalline $\mathrm{SiC}$ calculated on a 32-atom supercell; notice that 


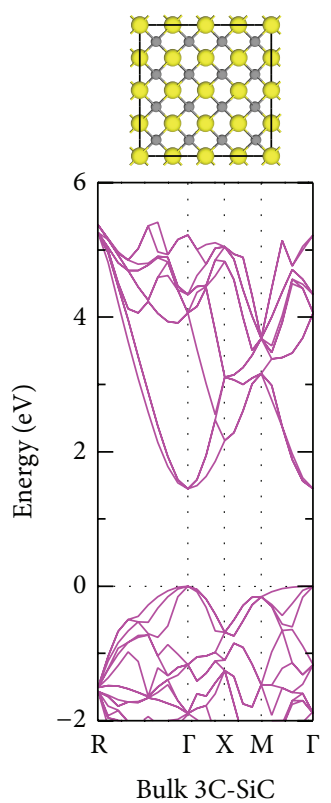

(a)

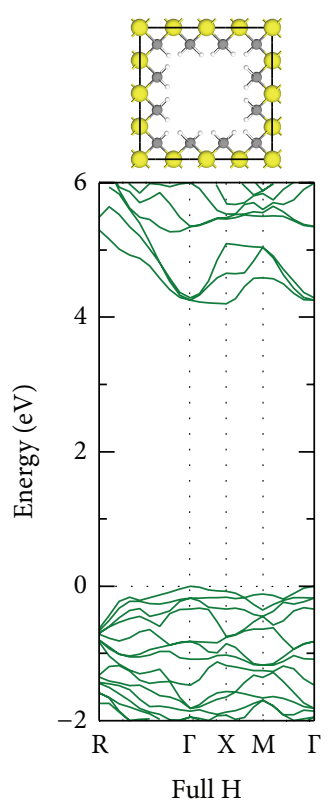

(b)

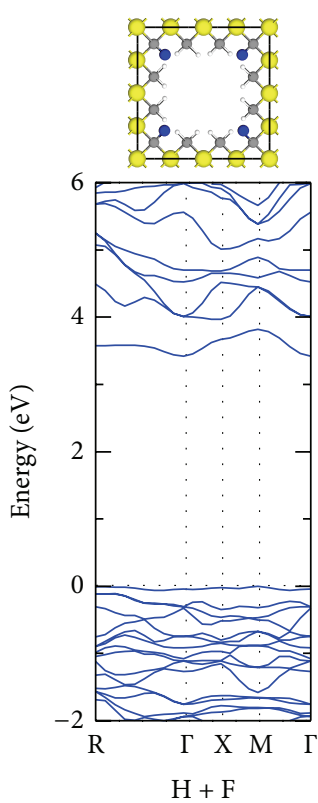

(c)

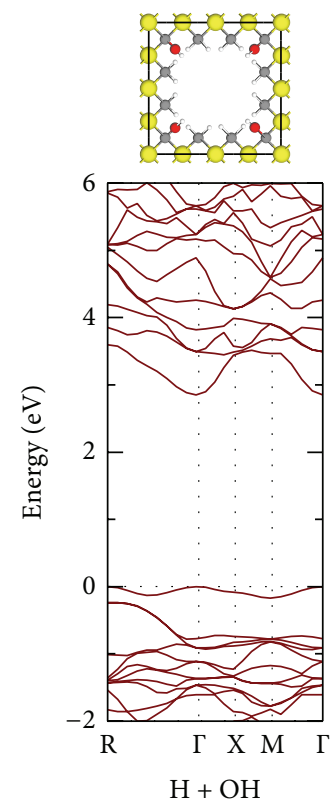

(d)

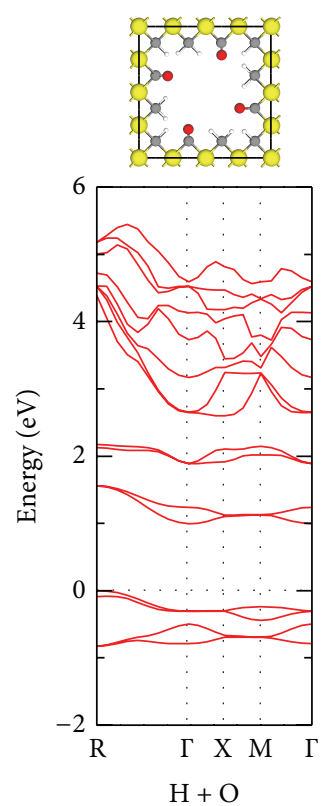

(e)

Figure 2: Electronic band structures of (a) bulk 3C-SiC 32-atom supercell and the C-phase pSiC surfaces with (b) full H, (c) H+F, (d) H+ OH, and (e) $\mathrm{H}+\mathrm{O}$ passivation at the surface. The respective optimized structures are shown in the top panel.

the gap is direct due to the folding of the Brillouin zone. The materials with full $\mathrm{H}$ and partial $\mathrm{F}$ and $\mathrm{OH}$ saturations (Figures 2(a), 2(b), and 2(c), resp.) feature a direct band gap, whereas that featuring double-bonded $\mathrm{O}$ terminal groups on the surface are characterized by an indirect band gap. Furthermore, the $\mathrm{F}, \mathrm{OH}$, and $\mathrm{O}$ cases exhibit decreases in the band gap energy of $18.61,32.23$, and $76.36 \%$, respectively, compared to the full $\mathrm{H}$-terminated $\mathrm{pSiC}$ band gap. The decrease in band gap energy in the $\mathrm{H}+\mathrm{F}$ case can be attributed to the $\mathrm{C}-\mathrm{F}$ bond, which is highly stable due to the electrostatic attraction between the polarized $\mathrm{C}$ and $\mathrm{F}$ atoms, thus reducing the charge transfer between Si and C, which reduces the band gap energy [23]. This situation can be understood either in terms of electrostatic interactions or by considering the stereoelectronic interactions with neighboring bonds or lone pairs. For the $\mathrm{OH}$ passivation, the lower band gap could be a result of the higher reactivity of the $\mathrm{C}-\mathrm{OH}$ bond compared to the $\mathrm{C}-\mathrm{F}$ bond. The $\mathrm{C}-\mathrm{OH}$ bond has only two lone pairs, which causes an increased repulsion between the electrons due to the high electric charge, hence creating additional states in the band gap. The drastic reduction of the band gap energy and the indirect feature in the $\mathrm{H}+\mathrm{O}$ case could be due to the trap-like states in the band gap energy caused by the change from an $\mathrm{sp}^{3}$ to an $\mathrm{sp}^{2}$ hybridization of the $\mathrm{C}$ bond and the additional $\mathrm{p}$ orbitals introduced by the $\mathrm{C}=\mathrm{O}$, where the $\mathrm{C}$ gains a more positive partial charge and the $\mathrm{O}$ possesses a partial negative charge $[24,25]$.

Figure 3 presents the evolution of the band gap energy with respect to the number of passivation agents other than $\mathrm{H}$ per supercell. In all cases, the energy gap of the C-phase $\mathrm{pSiC}$ decreased with the addition of the different passivation agents. The decrease of the band gap energy for the $\mathrm{H}+\mathrm{F}$ case can be explained in terms of the nature of the $\mathrm{C}-\mathrm{F}$ bond, where the high electronegativity of $\mathrm{F}$ (which is the most electronegative element in the periodic table) provides the $\mathrm{C}-\mathrm{F}$ bond with a significant polarity. When $\mathrm{F}$ is attached to $\mathrm{C}$, the resulting bond is strong and unreactive [26]. The $\mathrm{C}-\mathrm{F}$ bond is $43 \%$ ionic [27], and thus it is highly polarized (with $\mathrm{C}^{\delta+}$ and $\mathrm{F}^{\delta-}$ ); this high polarity suppresses the fluorine lone pair donation [28]. The electron density was observed to accumulate in the regions near F, thus establishing the highly ionic character of this bond. A similar behavior can be observed in the $\mathrm{H}+\mathrm{OH}$ case. Increasing the number of $\mathrm{OH}$ radicals reduces the band gap energy, illustrating the polar nature of the $\mathrm{C}-\mathrm{OH}$ bond.

The evolution of the $\mathrm{H}+\mathrm{O}$ case exhibits an increased reduction in the band gap energy compared to the $\mathrm{H}+\mathrm{F}$ and $\mathrm{H}+\mathrm{OH}$ cases; this trend can be caused by the replacement of $\mathrm{C}-\mathrm{H}_{2}$ for $\mathrm{C}=\mathrm{O}$, which involves a hybridization change of the $\mathrm{C}$ atom, as mentioned previously. This typically unsatisfactory substitution is based on the shape and smaller bonding-antibonding splitting due to the weaker $\mathrm{C}=\mathrm{O}$ bond; therefore, it is considered a defect at the surface.

To verify the most stable surface passivation, formation energies calculations were performed using the following expression [29]:

$$
E_{\mathrm{F}}=E_{\mathrm{pSiC}}-\sum_{i=\mathrm{Si}, \mathrm{C}, \mathrm{O}, \mathrm{H}, \mathrm{F}} n_{i} \mu_{i},
$$

where $E_{\mathrm{pSiC}}$ is the total energy of the passivated $\mathrm{pSiC}$ and $n_{i}$ and $\mu_{i}$ are the number of atoms per supercell and the chemical potential of the different chemical species used $(\mathrm{Si}, \mathrm{C}, \mathrm{O}, \mathrm{H}$, and $\mathrm{F}$ ), respectively. The chemical potentials were calculated using the bulk fcc structures of Si and $\mathrm{C}$ and molecular O, 
TABLE 1: Calculated optimized bond lengths and angles of the full $\mathrm{H}$ passivated $\mathrm{pSiC}$ with $40.6 \%$ porosity compared to the $\mathrm{H}+\mathrm{F}$ and $\mathrm{H}+$ $\mathrm{OH}$ passivation (bond length in $\AA$, bond angles in ${ }^{\circ}$ ).

\begin{tabular}{|c|c|c|c|c|c|c|c|c|c|c|c|}
\hline \multicolumn{4}{|c|}{ Full $\mathrm{H}$ passivated } & \multicolumn{4}{|c|}{$\mathrm{H}+\mathrm{F}$ passivated } & \multicolumn{4}{|c|}{$\mathrm{H}+\mathrm{OH}$ passivated } \\
\hline \multicolumn{2}{|c|}{ Bond length } & \multicolumn{2}{|c|}{ Bond angle } & \multicolumn{2}{|c|}{ Bond length } & \multicolumn{2}{|c|}{ Bond angle } & \multicolumn{2}{|c|}{ Bond length } & \multicolumn{2}{|c|}{ Bond angle } \\
\hline $\mathrm{H} 1-\mathrm{Cl}$ & 1.088 & Si5-C1-H1 & 104.564 & $\mathrm{~F} 4-\mathrm{C} 1$ & 1.504 & $\mathrm{Si} 5-\mathrm{C} 1-\mathrm{F} 4$ & 95.478 & $(\mathrm{OH}) 4-\mathrm{Cl}$ & 1.515 & $\mathrm{Si} 5-\mathrm{C} 1-(\mathrm{OH}) 4$ & 97.403 \\
\hline Sil-C1 & 1.967 & Sil-C1-H1 & 108.264 & Sil-C1 & 2.131 & Sil-C1-F4 & 120.533 & Sil-C1 & 2.158 & Sil-C1-(OH)4 & 122.176 \\
\hline $\mathrm{H} 6-\mathrm{C} 4$ & 1.088 & $\mathrm{Si} 4-\mathrm{C} 4-\mathrm{H} 6$ & 104.564 & F1-C4 & 1.504 & Si4-C4-F1 & 95.478 & $(\mathrm{OH}) 1-\mathrm{C} 4$ & 1.515 & $\mathrm{Si} 4-\mathrm{C} 4-(\mathrm{OH}) 1$ & 97.403 \\
\hline Sil-C4 & 1.967 & Sil-C4-H6 & 108.264 & Sil-C4 & 2.131 & Sil-C4-F1 & 120.533 & Sil-C4 & 2.158 & Sil-C4-(OH)1 & 122.176 \\
\hline H11-C7 & 1.088 & Si7-C7-H11 & 104.564 & F3-C7 & 1.504 & Si7-C7-F3 & 95.478 & $(\mathrm{OH}) 3-\mathrm{C} 7$ & 1.515 & Si7-C7-(OH)3 & 97.403 \\
\hline Sil-C7 & 1.967 & Sil-C7-H11 & 108.264 & Sil-C7 & 2.131 & Si1-C7-F3 & 120.533 & Sil-C7 & 2.158 & Sil-C7-(OH)3 & 122.176 \\
\hline $\mathrm{H} 16-\mathrm{C} 10$ & 1.088 & Si7-C10-H6 & 104.564 & $\mathrm{~F} 2-\mathrm{C} 10$ & 1.504 & Si7-C10-F2 & 95.478 & $(\mathrm{OH}) 2-\mathrm{C} 10$ & 1.515 & $\mathrm{Si} 7-\mathrm{C} 10-(\mathrm{OH}) 2$ & 97.403 \\
\hline Sil-C10 & 1.967 & Si1-C10-H6 & 104.564 & Sil-C10 & 2.131 & Sil-C10-F2 & 120.533 & Sil-C10 & 2.158 & Sil-C10-(OH)2 & 122.176 \\
\hline- & - & $\mathrm{Si} 3-\mathrm{C} 3-\mathrm{Si} 4$ & 119.137 & - & - & $\mathrm{Si} 3-\mathrm{C} 3-\mathrm{Si} 4$ & 121.515 & - & - & Si3-C3-Si4 & 121.608 \\
\hline - & - & Si4-C3-H5 & 109.153 & - & - & $\mathrm{Si} 4-\mathrm{C} 3-\mathrm{H} 5$ & 106.965 & - & - & Si4-C3-H5 & 107.574 \\
\hline
\end{tabular}

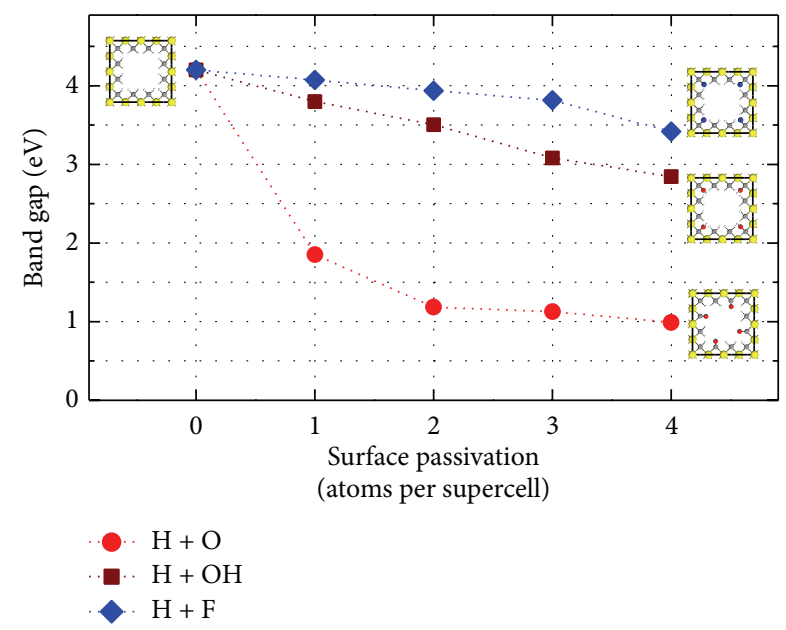

Figure 3: Changes of the band gap energy with respect to the number of passivation agents other than $\mathrm{H}$ at the surface per supercell. The circles represent $\mathrm{H}+\mathrm{O}$, the squares represent $\mathrm{H}+\mathrm{OH}$, and the diamonds represent $\mathrm{H}+\mathrm{F}$ passivation. In the inset, the limit case models for the $\mathrm{H}+\mathrm{X}$ passivation (where $\mathrm{X}$ represent $\mathrm{F}, \mathrm{O}$, or $\mathrm{OH})$ are shown.

$\mathrm{H}$, and F. The results are summarized in Figure 4, where gradual $\mathrm{F}$ passivation increases the formation energy to a positive value of $2 \mathrm{eV}$, thus indicating destabilization of the structure, whereas the $\mathrm{O}$ and $\mathrm{OH}$ passivations exhibit a gradual decrease in the formation energy with respect to the full $\mathrm{H}$ case, indicating that the structure is further stabilized by the insertion of $\mathrm{O}$ in either radical $(\mathrm{OH})$ or atomic $(=\mathrm{O})$ form. All of the pores with $\mathrm{H}+\mathrm{OH}$ and $\mathrm{H}+\mathrm{O}$ passivation have negative formation energy values indicating energetically favorable structures, with the four double-bonded $\mathrm{O}$ atoms per supercell being the most stable configuration. These results are of great importance in the characterization of $\mathrm{pSiC}$, as it is expected that a $\mathrm{C}=\mathrm{O}$ bond would be favored over an $\mathrm{OH}$ or an $\mathrm{F}$ substituent in an $\mathrm{O}$-rich environment.

We performed a geometry optimization of all structures to study the changes in the structure of pSiC due to the insertion of the different passivation agents. Figures 5(a),

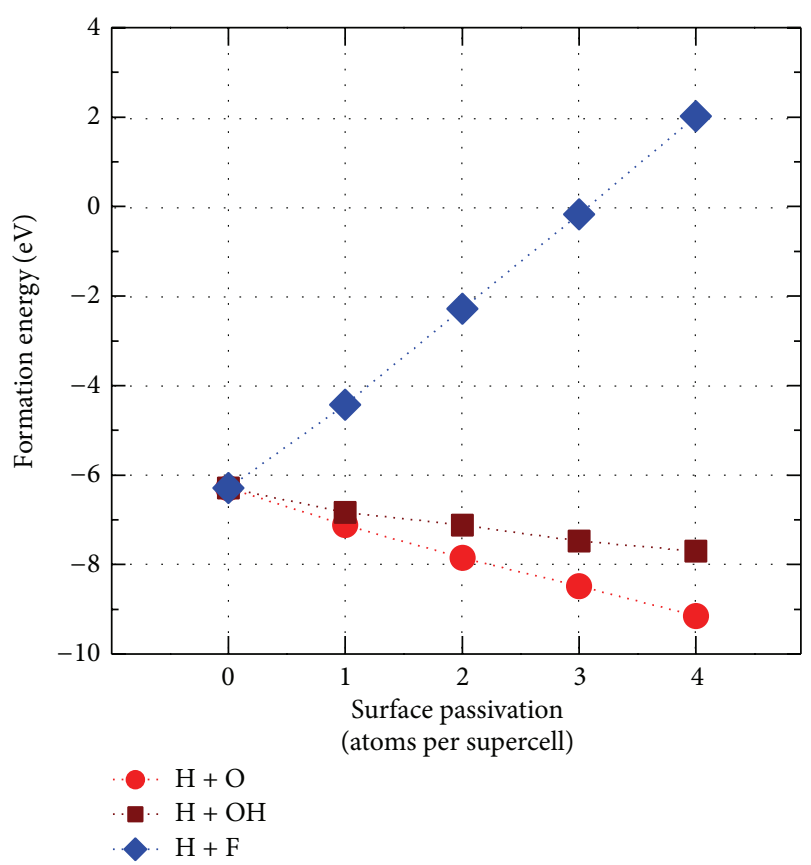

Figure 4: Evolution of the formation energy of $\mathrm{pSiC}$ with $\mathrm{H}+\mathrm{O}$ (circles), $\mathrm{H}+\mathrm{OH}$ (squares), and $\mathrm{H}+\mathrm{F}$ (diamonds) passivations with respect to the number of passivation agents other than $\mathrm{H}$ per supercell.

5(b), and 5(c) present the structural changes of pSiC with the limit cases of full $\mathrm{H}, \mathrm{H}+\mathrm{F}$, and $\mathrm{H}+\mathrm{OH}$ passivation, respectively; the most relevant structural parameters, bond lengths, and bond angles are reported in Table 1.

Table 1 indicates that a similar structural deformation is observed in the $\mathrm{H}+\mathrm{F}$ and $\mathrm{H}+\mathrm{OH}$ cases; the $\mathrm{Cl}-\mathrm{Sil}$ bond has an expansion of $8.33 \%$ for the $\mathrm{H}+\mathrm{F}$ passivation, whereas it has an expansion of $9.7 \%$ for the $\mathrm{H}+\mathrm{OH}$ passivation compared to the same bond in the full $\mathrm{H}$ passivation. Additionally, the expansion of the $\mathrm{C} 1-\mathrm{F} 4$ bond length is $38 \%$ in the $\mathrm{H}+\mathrm{F}$ passivation, whereas it is $39.24 \%$ in the $\mathrm{C} 1-(\mathrm{OH}) 4$ bond with respect to the $\mathrm{C} 1-\mathrm{H} 1$ bond in the full $\mathrm{H}$ passivation. A small deviation in the bond angle with respect to the ideal angle of 


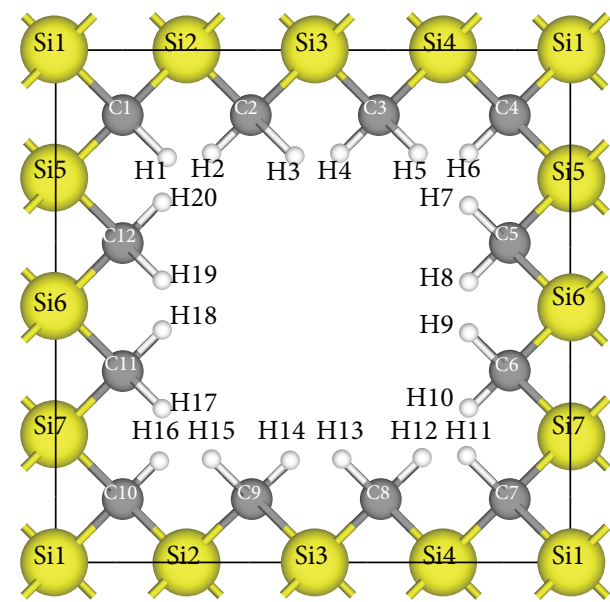

(a)

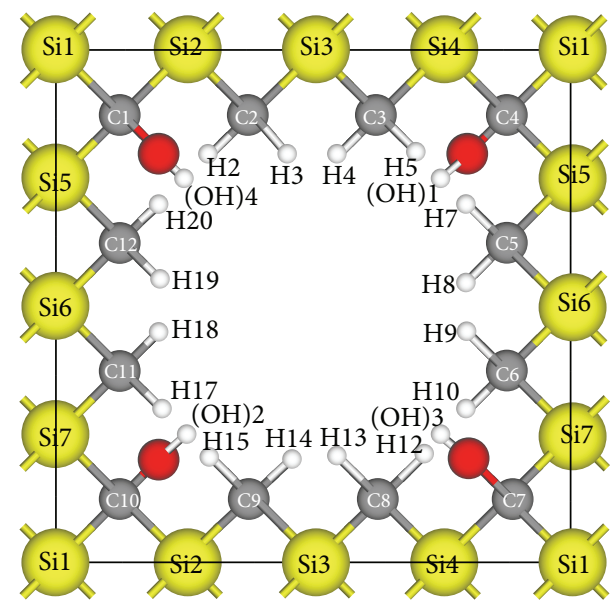

(c)

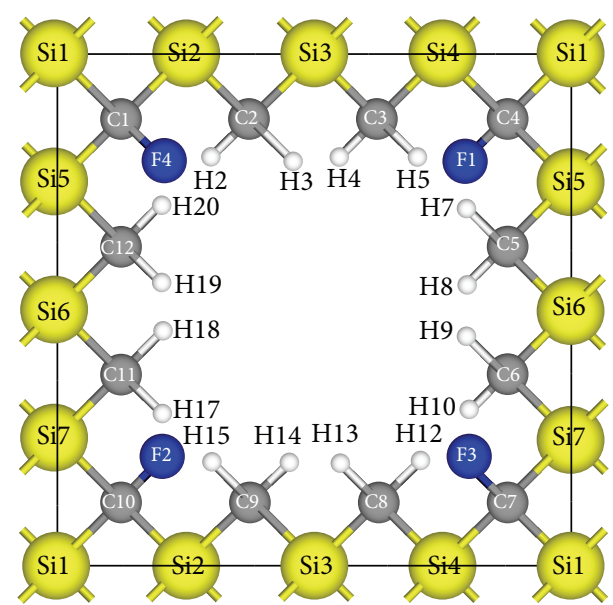

(b)

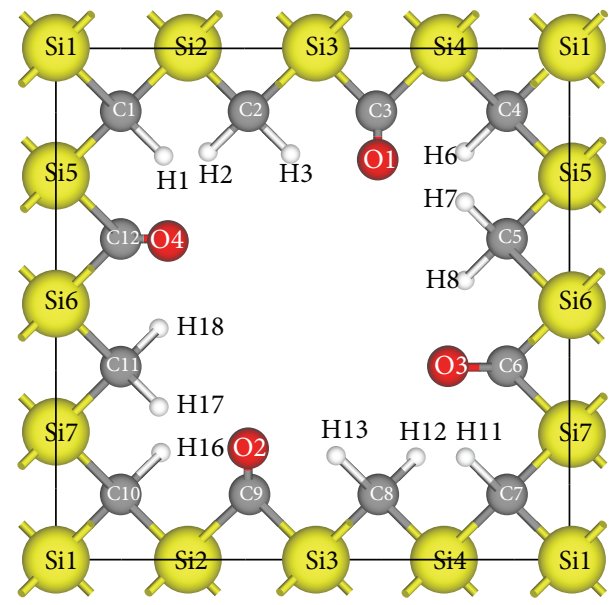

(d)

FIGURE 5: Structural changes of $\mathrm{pSiC}$ with the limit cases of (a) full $\mathrm{H}$, (b) $\mathrm{H}+\mathrm{F},(\mathrm{c}) \mathrm{H}+\mathrm{OH}$, and (d) $\mathrm{H}+\mathrm{O}$ passivation are depicted. Each atom is labeled to more clearly visualize the data in Tables 1 and 2 .

$\mathrm{sp}^{3}$ hybridization $\left(109.5^{\circ}\right)$ was observed, for instance, in the full $\mathrm{H}$ structure, the angles between $\mathrm{Si} 3-\mathrm{C} 3-\mathrm{Si} 4\left(119.137^{\circ}\right)$ or Si4-C3-H5 $\left(109.153^{\circ}\right)$. This divergence could be due to the different atomic radii of the atoms that formed these bonds $(\mathrm{Si}=1.17, \mathrm{C}=0.77$, and $\mathrm{H}=0.32 \AA)$. The bond angles for the $\mathrm{H}+\mathrm{F}$ passivation also presented some variation, particularly the Sil-C1-F4 bond angle, which increased by $11.3 \%$, whereas the Si5-C1-F4 bond angle decreased 8.6\% compared to the Sil-C1-H1 bond of the full $\mathrm{H}$ case; furthermore, for the $\mathrm{H}+\mathrm{OH}$ material, the corresponding Sil- $\mathrm{Cl}-(\mathrm{OH}) 4$ angle increased by $16.8 \%$ and the Si5-C1- $(\mathrm{OH}) 4$ decreased by $6.8 \%$.

According to the previously discussed observations, the bond length appears to depend on the difference between the electronegativities of the bonded atoms; the bond is shorter if the difference is large, as is the case for $\mathrm{C}-\mathrm{F}, \mathrm{C}=\mathrm{O}$, and $\mathrm{C}-$ $\mathrm{OH}$ [30]. The electronegative nature of $\mathrm{F}$ generates a high polarity in the $\mathrm{C}-\mathrm{F}$ bond; it also causes the three lone pairs of the $\mathrm{F}$ to be held tightly near the nucleus of the atom, which hinders their ability to act as charge donors. The C$\mathrm{F}$ bond interacts with its environment through electrostatic interactions (dipole-dipole or charge-dipole) [26], forming weak intermolecular bonds with nearby $\mathrm{H}$ atoms [28]. Thus, the bond angles and bond length modifications of the $\mathrm{C}$ atoms and their attached passivation agents can be explained using valence shell electron pair repulsion (VSEPR) theory [30]. In the $\mathrm{H}+\mathrm{F}$ case, the $\mathrm{C}-\mathrm{F}$ bond has three lone pairs of electrons, which cause great accumulation of the charge density around the $\mathrm{F}$ atom, producing a strong electrostatic repulsion between the electrons that constitute the $\mathrm{C}-\mathrm{F}$ bond and forcing the atoms to approach each other. This behavior is especially apparent in the $\mathrm{Cl}-\mathrm{F} 4$ bond, which has a smaller bond length than the $\mathrm{Cl}-\mathrm{Sil}$ bond. The $\mathrm{H}+\mathrm{OH}$ case is analogous to the $\mathrm{H}+\mathrm{F}$ case because the $\mathrm{O}$ atoms have two lone pairs of electrons, and thus the $\mathrm{Cl}-(\mathrm{OH}) 4$ bond length is smaller than that of the Sil-Cl bond.

Table 2 summarizes the structural changes of the $\mathrm{pSiC}$ with $\mathrm{H}+\mathrm{O}$ passivation (Figure 5(d)) compared to the full $\mathrm{H}$ case.

The $\mathrm{H}+\mathrm{O}$ passivation illustrates that the $\mathrm{C} 3$ changes to an $\mathrm{sp}^{2}$ hybridization, being bonded to three different atoms, forming two single bonds with two surrounding $\mathrm{Si}$ (Si3 and $\mathrm{Si} 4)$ and a double bond with $\mathrm{O}(\mathrm{C} 3=\mathrm{O} 1)$. This double bond 
TABLE 2: Calculated optimized bond lengths and angles of the $\mathrm{H}+\mathrm{O}$ passivated $\mathrm{pSiC}$ with $40.6 \%$ porosity compared to the full $\mathrm{H}$ passivated case (bond length in $\AA$, bond angles in ${ }^{\circ}$ ).

\begin{tabular}{lcccccc}
\hline \multicolumn{2}{c}{ Bond length } & \multicolumn{2}{c}{ Bull H passivated } & \multicolumn{2}{c}{ Bond length } & \multicolumn{2}{c}{$\mathrm{H}+$ O passivated } \\
\hline Si3-C3 & 1.92 & Si3-C3-Si4 & 119.137 & Si3-C3 & 1.995 & Si3-C3-O1 \\
Si4-C3 & 1.938 & Si3-C3-H4 & 111.512 & Si4-C3 & 2.026 & Si4-C3-O1 \\
H4-C3 & 1.095 & Si3-C3-H5 & 105.623 & O1-C3 & 1.225 & Si3-C3-Si4 \\
Si3-C9 & 1.92 & H5-C3-H4 & 103.874 & Si3-C9 & 1.995 & Si6-C6-O3 \\
Si2-C9 & 1.938 & Si4-C3-H4 & 106.512 & Si2-C9 & 2.026 & Si7-C6-O3 \\
H14-C9 & 1.095 & Si7-C6-Si6 & 119.137 & O2-C9 & 1.225 & Si6-C6-Si7 \\
Si7-C6 & 1.938 & Si7-C6-H10 & 109.153 & Si6-C6 & 1.994 & Si3-C9-O2 \\
H9-C6 & 1.095 & H9-C6-H10 & 103.874 & Si7-C6 & 2.026 & Si2-C9-O2 \\
H10-C6 & 1.078 & Si7-C6-H9 & 106.512 & O3-C6 & 1.225 & Si2-C9-Si3 \\
Si6-C12 & 1.92 & Si2-C9-Si3 & 119.137 & Si6-C12 & 1.994 & Si6-C12-O4 \\
Si5-C12 & 1.938 & Si3-C9-H14 & 111.512 & Si5-C12 & 2.026 & Si5-C12-O4 \\
H19-C12 & 1.095 & Si3-C9-H15 & 105.623 & O4-C12 & 1.225 & Si5-C12-Si6 \\
\hline
\end{tabular}

is formed by the overlap of the $\mathrm{sp}^{2}$ orbitals of $\mathrm{C}$ and $\mathrm{O}$, thus forming a sigma bond and pi bond; this result is confirmed by the angles between Si3-C3-O1 $\left(120.6^{\circ}\right)$, Si4-C3-O1 $\left(118.6^{\circ}\right)$, and $\mathrm{Si3}-\mathrm{C} 3-\mathrm{Si} 4\left(119.8^{\circ}\right)$, which are close to the ideal angle of $\mathrm{sp}^{2}$ hybridization $\left(120^{\circ}\right)$. This pi bond produces a highly reactive region because it has a lower energy than sigma bonds.

Another important feature is that the bond length between $\mathrm{C}$ and $\mathrm{Si}$ increases with respect to the full $\mathrm{H}$ case, being greater than that of the $\mathrm{C}=\mathrm{O}$ bond. The two lone electron pairs of $\mathrm{O}$ justify this difference in bond length.

Finally, Figure 6 presents the volume evolution with respect to the number of different passivation agents other than $\mathrm{H}$ per supercell. With respect to the $\mathrm{H}$ passivation, the $\mathrm{H}+\mathrm{F}$ and $\mathrm{H}+\mathrm{OH}$ cases have a volume expansion that increases almost linearly with the addition of $\mathrm{F}$ and $\mathrm{OH}$. This observation can be explained by the increase in the length of the $\mathrm{C} i-\mathrm{F} j(i=1,4,7,10$ and $j=1,2,3,4)$ bonds and the increase in the length of the Ci-Sil bonds $(i=1,4,7,10)$, whereas the analogous bonds undergo a similar expansion in the $\mathrm{H}+\mathrm{OH}$ case. Compared to the $\mathrm{H}+\mathrm{F}$ and $\mathrm{H}+\mathrm{OH}$ cases, the $\mathrm{H}+\mathrm{O}$ passivation has a relatively low expansion, possibly due to the lower number of $\mathrm{H}$ atoms per supercell and the change of hybridization of the $\mathrm{C}=\mathrm{O}$ bonds, which creates a planar triangular structure.

\section{Conclusions}

In summary, we have studied the structural and electronic properties of porous silicon carbide through a first-principles density functional theory scheme. The results demonstrate that the electronic properties of $\mathrm{pSiC}$ are greatly influenced by the surface passivation of the porous structure. The $\mathrm{H}+$ $\mathrm{O}$ passivation exhibits a drastic reduction in the band gap energy compared with the full $\mathrm{H}$ and $\mathrm{H}+\mathrm{F}$ and $\mathrm{H}+\mathrm{OH}$ passivations due to the different hybridization of the $\mathrm{C}=\mathrm{O}$ bond. However, the formation energy calculations indicate that the most stable configuration is the $\mathrm{H}+\mathrm{O}$ passivation with four oxygen atoms per supercell. The structural analysis

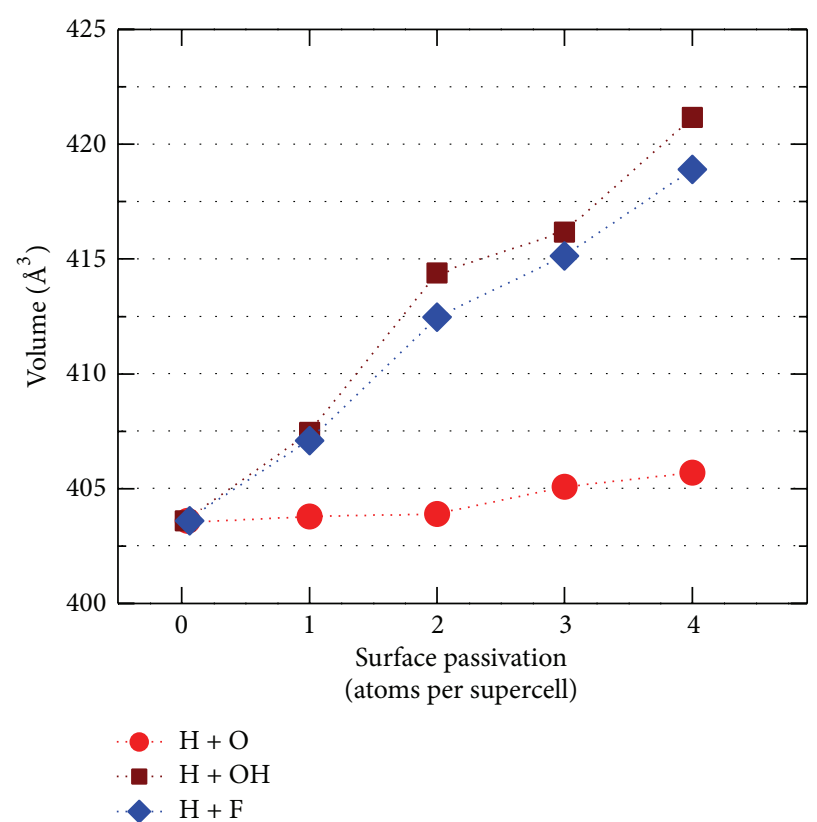

FIGURE 6: The volumes of the C-phase pSiC with respect to the number of passivation agents other than $\mathrm{H}$ per supercell are shown. The circles, squares, and diamonds represent $\mathrm{H}+\mathrm{O}, \mathrm{H}+\mathrm{OH}$, and $\mathrm{H}+\mathrm{F}$ passivation, respectively.

indicates a great dependence of the bond characteristics on the electronegativity of the bonded atoms, where a more polar bond produces shorter bond lengths, as seen in the $\mathrm{H}+\mathrm{F}$ case. Furthermore, the $\mathrm{H}+\mathrm{O}$ passivation had the lower volume expansion rate. All of the structural and electronic changes could be explained using VSEPR theory, where the number of lone pairs on the surface changes the reactivity of the bonds. These results could be important in the characterization of pSiC because they provide insight into the most stable surface configurations and their electronic structures. 


\section{Conflict of Interests}

The authors declare that there is no conflict of interests regarding the publication of this paper.

\section{Acknowledgments}

This work was supported by the Secretaría de Ciencia, Tecnología e Innovación del Distrito Federal (SECITI-DF) by projects ICyTDF/PICSO12-085 and ICyTDF/325/2011 and multidisciplinary project 2012-1439 from SIP-Instituto Politécnico Nacional.

\section{References}

[1] N. Naderi and M. R. Hashim, "Visible-blind ultraviolet photodetectors on porous silicon carbide substrates," Materials Research Bulletin, vol. 48, no. 6, pp. 2406-2408, 2013.

[2] X. Liu, G. Sun, B. Liu et al., "Growth of hexagonal columnar nanograin structured $\mathrm{SiC}$ thin films on silicon substrates with graphene-graphitic carbon nanoflakes templates from solid carbon sources," Materials, vol. 6, no. 4, pp. 1543-1553, 2013.

[3] S.-H. Lee, S.-M. Yun, S. J. Kim, S.-J. Park, and Y.-S. Lee, "Characterization of nanoporous $\beta$-SiC fiber complex prepared by electrospinning and carbothermal reduction," Research on Chemical Intermediates, vol. 36, no. 6-7, pp. 731-742, 2010.

[4] K.-S. Kim and G.-S. Chung, "Characterization of porous cubic silicon carbide deposited with $\mathrm{Pd}$ and $\mathrm{Pt}$ nanoparticles as a hydrogen sensor," Sensors and Actuators B: Chemical, vol. 157, no. 2, pp. 482-487, 2011.

[5] K.-S. Kim and G.-S. Chung, "Fast response hydrogen sensors based on palladium and platinum/porous 3C-SiC Schottky diodes," Sensors and Actuators B: Chemical, vol. 160, no. 1, pp. 1232-1236, 2011.

[6] N. Naderi, M. R. Hashim, K. M. A. Saron, and J. Rouhi, "Enhanced optical performance of electrochemically etched porous silicon carbide," Semiconductor Science and Technology, vol. 28, no. 2, Article ID 025011, 2013.

[7] K.-H. Lee, S.-K. Lee, and K.-S. Jeon, "Photoluminescent properties of silicon carbide and porous silicon carbide after annealing," Applied Surface Science, vol. 255, no. 8, pp. 4414-4420, 2009.

[8] N. Naderi and M. R. Hashim, "Effect of different current densities on optical properties of porous silicon carbide using photo-electrochemical etching," Materials Letters, vol. 88, pp. 65-67, 2012.

[9] O. Bisi, S. Ossicini, and L. Pavesi, "Porous silicon: a quantum sponge structure for silicon based optoelectronics," Surface Science Reports, vol. 38, no. 1-3, pp. 1-126, 2000.

[10] W. Q. . Huang, F. Jin, H. X. Wang et al., "Stimulated emission from trap electronic states in oxide of nanocrystal Si," Applied Physics Letters, vol. 92, Article ID 221910, 2008.

[11] W.-Q. Huang, H.-X. Wang, F. Jin, and C.-J. Qin, “Trap states in oxidation layer of nanocrystal Si," Chinese Physics B, vol. 17, no. 10, pp. 3753-3758, 2008.

[12] A. Trejo, M. Calvino, E. Ramos, and M. Cruz-Irisson, "Computational simulation of the effects of oxygen on the electronic states of hydrogenated 3C-porous SiC," Nanoscale Research Letters, vol. 7, no. 1, p. 471, 2012.
[13] A. Trejo and M. Cruz-Irisson, "Computational modeling of the size effects on the optical vibrational modes of $\mathrm{H}$-terminated $\mathrm{Ge}$ nanostructures," Molecules, vol. 18, no. 4, pp. 4776-4785, 2013.

[14] H. Föll, J. Carstensen, and S. Frey, "Porous and nanoporous semiconductors and emerging applications," Journal of Nanomaterials, vol. 2006, Article ID 91635, 10 pages, 2006.

[15] A. I. Diaz Cano, T. V. Torchynska, J. E. Urbina-Alvarez, G. R. Paredes Rubio, S. Jiménez Sandoval, and Y. V. Vorobiev, "Porous $\mathrm{SiC}$ layers on Si nanowire surface," Microelectronics Journal, vol. 39, no. 3-4, pp. 507-511, 2008.

[16] A. Catellani and G. Galli, "Theoretical studies of silicon carbide surfaces," Progress in Surface Science, vol. 69, no. 4-6, pp. 101124, 2001.

[17] W. Shin, W. Seo, O. Takai, and K. Koumoto, "Surface chemistry of porous silicon carbide," Journal of Electronic Materials, vol. 27, no. 4, pp. 304-307, 1998.

[18] S. J. Clark, M. D. Segall, C. J. Pickard et al., "First principles methods using CASTEP," Zeitschrift fur Kristallographie, vol. 220, no. 5-6, pp. 567-570, 2005.

[19] B. Hammer, L. B. Hansen, and J. K. Nørskov, "Improved adsorption energetics within density-functional theory using revised Perdew-Burke-Ernzerhof functionals," Physical Review B: Condensed Matter and Materials Physics, vol. 59, no. 11, pp. 7413-7421, 1999.

[20] D. R. Hamann, M. Schlüter, and C. Chiang, "Norm-conserving pseudopotentials," Physical Review Letters, vol. 43, no. 20, pp. 1494-1497, 1979.

[21] H. J. Monkhorst and J. D. Pack, "Special points for Brillouinzone integrations," Physical Review B, vol. 13, no. 12, pp. 5188$5192,1976$.

[22] B. G. Pfrommer, M. Côté, S. G. Louie, and M. L. Cohen, "Relaxation of crystals with the quasi-newton method," Journal of Computational Physics, vol. 131, no. 1, pp. 233-240, 1997.

[23] S. Saha and P. Sarkar, "Tuning the HOMO-LUMO gap of SiC quantum dots by surface functionalization," Chemical Physics Letters, vol. 536, pp. 118-122, 2012.

[24] J. Wang, L. Zhang, Q. Zeng, G. L. Vignoles, and L. Cheng, "Surface relaxation and oxygen adsorption behavior of different $\mathrm{SiC}$ polytypes: a first-principles study," Journal of Physics Condensed Matter, vol. 22, no. 26, Article ID 265003, 2010.

[25] M. Vörös, P. Deák, T. Frauenheim, and A. Gali, “The absorption of oxygenated silicon carbide nanoparticles," Journal of Chemical Physics, vol. 133, no. 6, Article ID 064705, 2010.

[26] L. Hunter, "The C-F bond as a conformational tool in organic and biological chemistry," Beilstein Journal of Organic Chemistry, vol. 6, article 38, 2010.

[27] J. L. Kiplinger, T. G. Richmond, and C. E. Osterberg, "Activation of carbon-fluorine bonds by metal complexes," Chemical Reviews, vol. 94, no. 2, pp. 373-431, 1994.

[28] D. O’Hagan, "Understanding organofluorine chemistry. An introduction to the C-F bond," Chemical Society Reviews, vol. 37, no. 2, pp. 308-319, 2008.

[29] B. Aradi, L. E. Ramos, P. Deák et al., "Theoretical study of the chemical gap tuning in silicon nanowires," Physical Review B: Condensed Matter and Materials Physics, vol. 76, no. 3, Article ID 035305, 2007.

[30] V. G. S. Box, "The molecular mechanics of quantized valence bonds," Journal of Molecular Modeling, vol. 3, no. 3, pp. 124-141, 1997. 

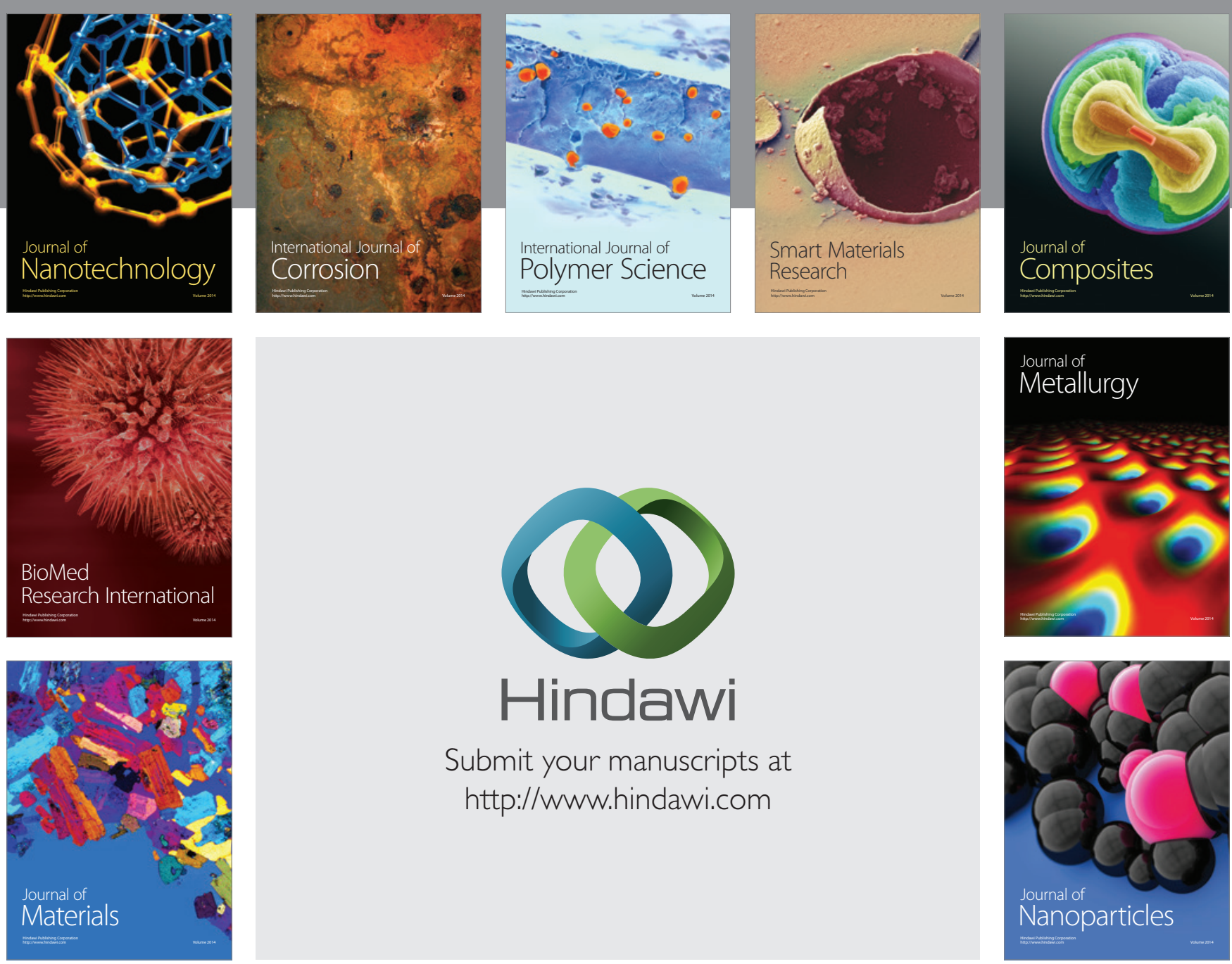

Submit your manuscripts at http://www.hindawi.com
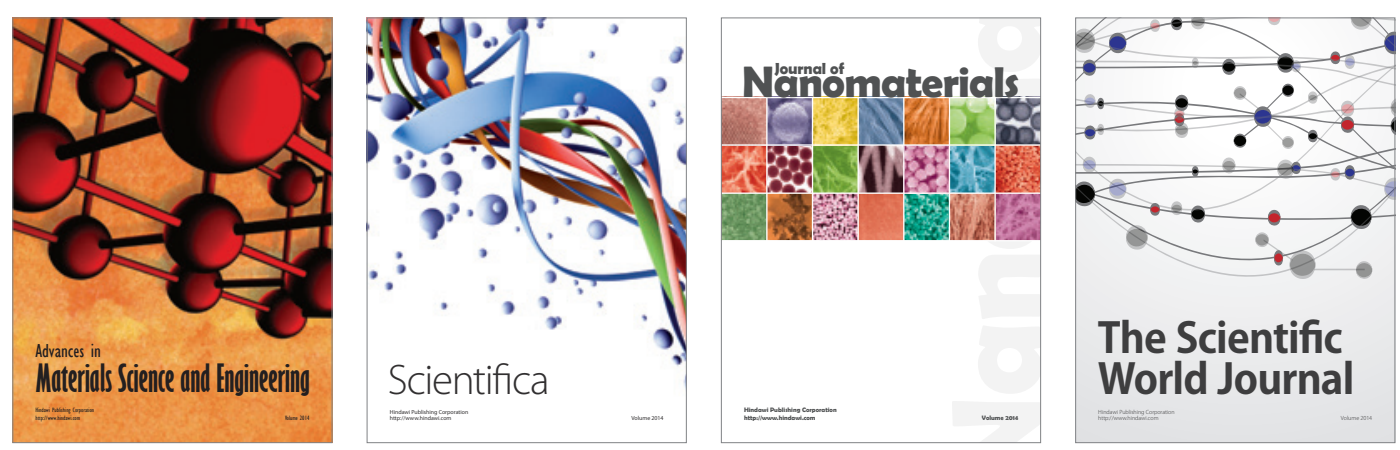

\section{The Scientific World Journal}
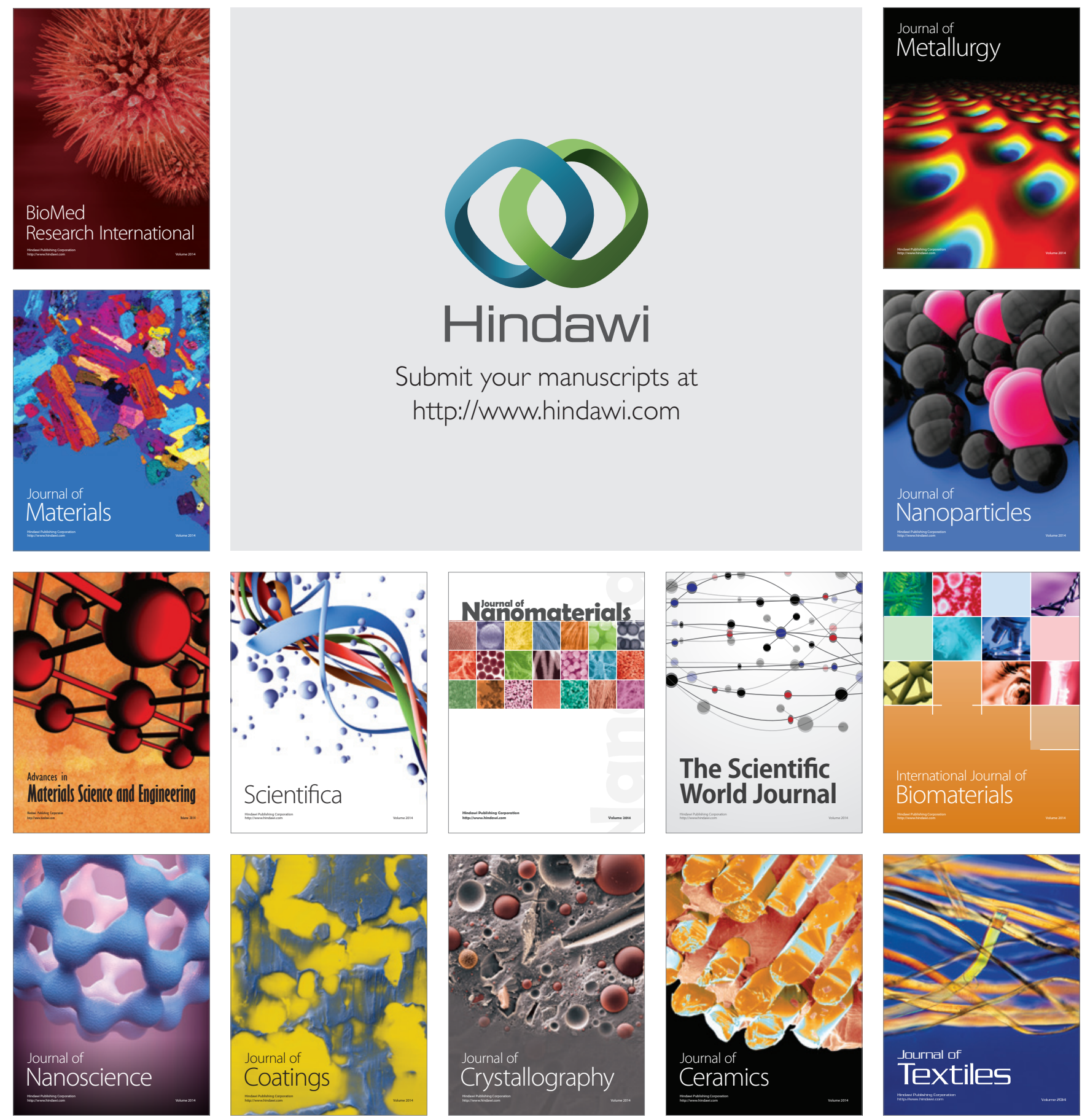